\title{
The Rural Electric Power Market Development Research
}

\author{
Wei Wei \\ North China Electric Power University, Beijing, 102206 \\ alanncepu@foxmail.com
}

Keywords: Power market; Rural power grid; Reform of electric power system

\begin{abstract}
Since 1998, China has implemented a large-scale rural power grid construction and transformation. In 2006, the transformation project of the first stage and the second stage has been basically completed. With the rapid development of power industry, rural power grid construction and transformation has achieved significant effects that rural production and living conditions improved a lot. Rural is the area that has the largest potential power demand in China. But for a long time, urban power grid's planning and construction in urban area are better in rural area. There are still many problems in the development of rural electric power market such as low power supply reliability, large line loss and so on, which have serious impacts on the development of rural electric power market. In order to solve the problems, related measures should be taken. Thus, to speed up the development of rural electric power market, correctly grasp the possible problems in the power system reform and gradually deepen the rural reform of electric power system have become the key to the development of electric power enterprise by collecting data, obtaining the power market information.
\end{abstract}

\section{The Process of Rural Electric Power Market Development}

The development of modern economy drives the development of rural economy, farmers living conditions are improved greatly, and electric power is becoming a hot spot of the rural market. So the electric power market has great development space. However, due to various reasons, the development of rural electric power market is restricted to some extent that it is not mature enough. So the study of rural development and the electric power market development has important practical significance.

Since 1998, China has implemented a large-scale rural power network construction and transformation. In 2006, the transformation project of the first stage and the second stage has been basically completed. The improving of rural production and living conditions are effectively promoted the growth of the rural electricity consumption.

During the 11th Five Year Plan, State Grid Corporation of China vigorously implement the "Sanxin" rural power development strategy to promote the construction of rural power grid. The cost on rural network reconstruction is totally more than 307.5 billion yuan to solve the using power questions of over 1.341 million households and 5.089 million people and build 407 new rural electrification counties. Standardization of rural construction level the team quality are improved. Take China Southern Power Grid as an example. It has invested 69100 million to make household electricity in Guangdong, guangxi, guizhou and hainan province.

Under the push of our government, the new round of rural power grid upgrading project in China progresses smoothly. Data shows that by the end of March 2012, the state has given national power grid companies 150.4 billion yuan to rural power grid construction. The total investment is 76.33 billion yuan.

\section{The Current Situation of Electricity Market in Rural Area}

(1) Electricity consumption level in rural areas is low. Rural population accounts for most of China's population. Take the statistical data of some county in 2005 as an example, the county has more than 1 million people, in which more than $90 \%$ are agricultural population with per capita living power consumption $96 \mathrm{kWh}$. Electricity consumption per person is less than $0.27 \mathrm{kWh}$ a day. 
There is a larger gap between it and $1 \mathrm{~kW}$ per person a day. Low level of rural electricity as a whole is a common phenomenon. Low level of rural electricity is a common phenomenon.

(2) Household appliances in rural areas speeds up quickly. With the development of economy in our country, the living standard of rural residents is improving. There are many household appliances popularizing in rural area families such as refrigerator, LCD TV, washing machine, computer, audio and so on. This could drive the development of consumption in rural areas and improve the level of using electricity.

(3) Enterprise has become big consumers of electric energy. Nowadays, Nearly $50 \%$ of electricity is used for industrial production in rural areas and the proportion is increasing. Along with the cost of human resources rising in recent years, many companies tend to turn to rural areas and the government investment in rural areas is also rising. Rural enterprises will become an important growth point of power consumption.

(4) The development of electricity using in rural areas has huge potential. Generally speaking, many economic development of rural areas is relatively outdated. With low level of electricity and backward industry, there are huge development space. Many families will gradually popularize the use of air conditioning, refrigerator and other household electrical appliances, which plays a role for raising the level of electricity in rural areas.

\section{The Problems Existing in the Current Power Market}

(1) The power distribution reliability in some areas still need to be improved. There are many potential safety hazards exist in rural area for power loads are imbalanced. The coverage of the power supply network of agricultural production is not so wide. Due to the backward rural economic development, transform grid funding is also limited. Therefore the reconstruction of rural electric grid has to tend to the power of peasants' lives, ignoring the construction of agricultural production power supply network.

(2) Part of the power supply line is too long, the power loss is big and the overload phenomenon is serious. Voltage quality remains to be improved. After upgrading of rural power grid, although network conditions of $10 \mathrm{KV}$ is improved, network conditions of $35 \mathrm{KV}$ and $110 \mathrm{KV}$ still have serious problems. The low voltage of system led to a lot of growth of line loss.

(3) The management of rural power network is difficult. The electric power enterprise quality service and power grid maintenance can't conduct normally for the economy in some areas lags behind relatively. Employees in rural areas don't have mature concept on rural marketing and their knowledge degree of marketization is not high enough. According to a research, $98 \%$ of them are urban electrician and related workers. Most of them don't have good education background high culture quality. Thus, it's difficult for them to perfect the power system in rural areas.

(4) The rural power grid has a single site to investment and financing mechanism so it is lack of energy. The price of rural electricity is high and it is lack of competition ability. The form of rural electricity is more than the city electricity price form, making the electric power price is more than the price in city.

(5) The equipment is obsolete and has small capacity. The design capacity of rural distribution transformer is insufficient. However, rural life production demand is becoming more, which result in the problem of overload.

\section{The Improvement of Rural Electric Power Market}

To Change the Old Ideas. Aiming at the reality that many farmers has low culture level, the staff should consider for them. Much work such as electricity knowledge popularization and difficult problem query should be included as their daily work. At the same time, professional service should be provided if need. To deal with the problems efficiently and accurately is the goal.

To Implement Services Around the Policy. Power and electricity price should be realized. Equity is really important. When the related policy published, relevant departments should 
strengthen the supervision to ensure implementation. If so, the electric market would be better and better.

To Speed Up the Power Grid Construction. With efficiency and benefit as the center, encourage rural workers to actively participate in management. We should continue to improve the rural electricity management system to make integrated management of county and village come true.

Make urban and rural power network have the same price and firmly establish a customer-focused business philosophy. As the formation of a buyer's market, customers put forward higher requirements on service quality, the power supply quality and the price level. Staff is expected to solve the user's practical difficulties and questions in time.

To Improve the Safety Responsibility System for Electricity. Nowadays, the age structure and the knowledge structure of some rural staff is difficult to adapt to the rural sustainable development in the long run, which brings difficulty to the cross-regional operation and reduce efficiency. Some graduates with higher education background should be send to the economically backward rural areas to enrich the troops of workers and replace the unqualified staff. In this way, the employment pressure is remitted and expand the power of rural staff team.

\section{An Example of Electricity Market Reform}

Taking the current situation of the rural electric power market in Jian, Jiangxi as an example. There are more than 100 families in the village Zhenyuan. The power network in Zhenyuan is constructed in 2006. The power is provided by a $50 \mathrm{KV}$ transformer. In recent years, the living qualities of villagers in Zhenyuan is improved a lot. Many villagers have bought High-power appliances. At the same time, electricity load is also booming. The original transformer and power supply line not only can't meet the living needs of the villagers, but also seriously restricts the development of the village economy.

Knowing the source of electricity difficulties, electric power Supply Company of Jian county take measures immediately. They came to Zhenyuan to take investigation and make specific measures for the problems. In early January, construction team came there to build new power line and change transformers. The power using problems in the village is quickly solved.

In addition to this, electric power Supply Company of Jian has launched a series of service measures named "warming Spring Festival family service". After having Active communication with the community, the company organize party members and cadres to service into community and village and post electricity service information. So that returned migrant workers can contact them in time. They also carry out appointment services to know the safety of power using in villagers' home. Their work has received the consistent high praise.

\section{References}

[1] Yuqi Wang, Xiaoxia Shang, Chen Wang. Rural Electricity Market Research in a Given Area. Scientific Management.pp:63-65.

[2] Qian Song. 2014. Rural Electric Power Market Analysis and Marketing Measures [J].Science and Technology Innovation. No.35, pp: 194

[3] Haifeng Cui, Shenye Yang. 2009. Organization and Development of Carrying out Directly Buying Electricity in Junior Power Market. SHA NXI ELECT RIC PO WER.No.6, pp: 68-72

[4] Hanhua Liu. 2006. Introduction to the development of rural electric power market. Journal of Wuhan electric Power Technical Collage.Vol.4, No.3, pp: 65-68

[5] Wenge Li. 2012. Try to Talk About the Rural Development and the Development of Electric Power Market. Development Strategy.pp:7-8 
[6] DianqingWang, Qiang Wu. 2011. Rural Electric Power Market Survey and Research.Technology and Market.Vol18, No.2, pp: 69-71

[7] Wenyan Chi. 2012. The Main Problems and Reform Measures of Rural China Electricity Market. Energy and Energy Conservation. Vol.6, pp: 21-22

[8] Junbin Qiao, Cuili Yu. 2009. Discussion on the Countryside Electric Power Market. Shanxi Electric Power. Vol.6, pp: 68-69

[9] Xin Zhang, Li Zhang, Peng Shen. 2010. To Develop Rural Electric Power Market in China Under the New Situation. Modern Enterprise Culture. Vol.12, pp: 21-22

[10] Xianyong Xiao.2004. Electric Power Market Marketing Principle. Beijing: China Electric Power Press. 